\title{
How Much of Usable Matrix is Necessary to Suppress Fragmentation Effect? An Individual Based Model of Population Extinction
}

Bruno Travassos-de-Britto ${ }^{1 *}$, José Miranda ${ }^{2}$, Pedro Rocha $^{3}$,

1 Department of Ecology, University of São Paulo, São Paulo City, SP, Brazil

2 Nuclear Geophysics Department, Federal University of Bahia, Salvador, BA, Brazil

3 Department of Zoology, Federal University of Bahia, Salvador, BA, Brazil

* Corresponding author

bruno.travassos@gmail.com

\section{Abstract}

The use of the matrix has been considered an important factor in landscape ecology, as it can change the relationship of the population with the configuration of the landscape. There are indications that the usability of the matrix is a factor that can help mitigate the effect of further fragmentation. Using a systematic way to assess the effect of matrix quality in fragmented landscapes could lead to a better understanding of this system. We built a computational individual based model capable of simulate bi-dimensional landscapes and individuals that inhabit that landscape. We explored how changes in the level of fragmentation and matrix quality affected time of permanence of a single population in the landscape. As the quality of the matrix changes from very unsuitable to very suitable, the number of situations in which fragmentation reduces the time of permanence of the population changes from frequent to rare. In addition, as most of the organisms can survive in a sub-optimum habitat, the cases in which fragmentation has 
real effect on populations' permanence are even fewer then stated by Fahrig. The result indicates that the proportion of intermediate habitat necessary to suppress fragmentation effect should follow the percentage of usability of these intermediate habitat until it falls under $50 \%$ of usability, and with less than $30 \%$ of usability, intermediate habitats are not able to suppress fragmentation effect. An index to measure the usability of elements of the matrix should be an important tool relating computational models and landscape management.

\section{Introduction}

For many years, ecological theory has ignored the role of spatial structure in its models (Pickett et al, 2010). With the advances of landscape ecology, several patterns of spatial structure and their effect on biodiversity are beginning to be identified, and habitat loss and fragmentation are intuitively associated with diversity loss (Saunders et al, 1991). In 1998, Fahrig used a computational model to assess the effect of habitat fragmentation and habitat loss when these factors are disassociated from one another. In this article, habitat amount was considered the proportion of the landscape comprised by a native physiognomy, and habitat fragmentation was evaluated as a measure of aggregation of the habitat in the landscape. In this sense, Fahrig could change the aggregation maintaining the same proportion of habitat, and Fahrig concluded that habitat fragmentation, when dissociated from habitat loss, only has an effect on populations' permanence in few scenarios $(0.4 \%$ of all combinations of parameters of the model). Fahrig also envisaged that most of the authors who found a strong effect of fragmentation on populations' permanence were confounding the effect of habitat loss with the effect of fragmentation per se (Fahrig, 1998). Later, Fahrig published a review of empirical articles that corroborated her hypothesis (Fahrig, 2003). In this review, Fahrig suggested that the effect of habitat fragmentation per se on species richness could be negative (Rosenberg et al, 1999), absent (Drolet et al, 1999 Hovel and Lipcius, 2001), or even positive (Bélisle et al, 2001, Weldon, 2006).

Despite Fahrig's conclusion, many studies have continued to show that the increase in habitat fragmentation decreases the probability of permanence of the population in the landscape (Harrisson et al, 2013, Holland and Bennett, 2010, Johnstone et al, 2010; 
Nimmo et al, 2013; Reino et al, 2013). However, the rare studies that have analyzed the $\quad 24$ effect of fragmentation per se used highly specialized organisms as models to test the hypothesis indicating that these organisms were, in fact, unable to use the matrix for most of their ecological needs. Studies using more than one taxon systematically have observed the effect of fragmentation on populations of specialized organisms and no effect on more generalized organisms (Didham et al, 1998, Summerville and Crist, 2001). This pattern suggests that the scenarios in which fragmentation empirically has been shown to affect populations' permanence are those few particular scenarios described by Fahrig. Thus, the pattern of a high number of empirical studies showing a negative relationship between fragmentation and permanence of populations is only true due to the bias of situations with fragmentation. Moreover, this pattern could lead to the wrong interpretation that fragmentation is an important factor causing loss of species when the cases in which this result is observed are rare in nature. Most animal species can obtain some type of resources from the matrix and rarely would die quickly without the chance to reproduce (Ewers and Didham, 2006).

Fahrig conceived matrix as a homogenous physiognomy of the landscape in which the fitness of individuals of the focal population would be minimum. However, the use of the matrix by the focal population has been considered an important factor affecting the relationship between fragmentation and permanence of this population (Ewers and Didham, 2006, Ricketts, 2001), suggesting that the population is able to use some elements of the matrix increasing its ability to persist in the landscape when not in its native environment. Ewers and Didham (2006) argued that a matrix is not a homogeneous environment and that the resources of the matrix can be utilized in two ways that favor the permanence of the population in the landscape. The matrix can provide a resource that is no longer available within the fragments of the native physiognomy (either by the absence itself or by competition). In this case, even though the resource may not be of the same quality of that found in the native physiognomy, it might be enough to increase the population's abundance, thus favoring the population permanence. Moreover, the matrix can have some elements that might be used as step-stonesf connecting fragments that otherwise would be beyond the dispersal capacity of individuals even if the matrix cannot provide an essential resource by itself. Such uses of the matrix could mitigate as much the effect of habitat loss as the effect of 
habitat fragmentation per se. Thus, a model that ignores the heterogeneity of the matrix is disregarding an important factor to predict the behavior of populations.

A frequent critic to spatial explicit computational models is the oversimplification of these models, which may lead to a lack of prevision power and consequently of applicability of such models (Wiegand et al, 2004). Although Fahrig's article has become one of the computational model studies most cited in landscape ecology (2000+ citations - All bases of Web of Science JCRR/ January 2016), one of its limitations, is that it disregards the matrix effect, as noted by the author herself: "Would the results be different under assumptions of a heterogeneous matrix? To answer this one would need to vary FRAG and the degree of matrix heterogeneity, and look for an effect of their interaction on survival time." (Fahrig, 1998). A model able to overcome this limitation could bring novel insights to the theoretical understanding of the effect of matrix quality, thereby adding to applicability and management on fragmented landscapes.

In the present study, we built a computational model based on Fahrig's model (Fahrig, 1998). In the original model, the landscape was conceived as a binary lattice with a favorable physiognomy (breeding habitat) and a hostile one (matrix). In our new version, we included a third physiognomy that had an intermediate hostility level between the breeding habitat and the matrix. In this study, we will refer to the favorable physiognomy as native physiognomy, to the hostile physiognomy (former matrix) as harsh physiognomy and to the intermediate as intermediate physiognomy. The union of the area covered by harsh physiognomy and intermediate physiognomy will be referred as matrix. We used Kearney's concept of habitat as follows: "a description of a physical place, at a particular scale of space and time, where an organism either actually or potentially lives" (Kearney, 2006). Each one of these three physiognomies could be biologically interpreted as follows: as a physiognomy where the focal organism's population evolved and adapted to and therefore where the organism fitness is higher (native physiognomy); as highly different physiognomy where the fitness of the organism is minimum (harsh physiognomy); or as a physiognomy that has intermediate characteristics between the native physiognomy and the harsh physiognomy (intermediate physiognomy). In our model, we varied the quality of the matrix by changing the proportion of harsh physiognomy and intermediate physiognomy on the 
landscape or by changing the usability level of the intermediate physiognomy, thereby making it more similar to the native physiognomy or to the harsh physiognomy.

The objective of this study was to extend Fahrig's model to investigate which type of matrix the fragmentation per se still had an effect on the permanence of populations. We used the same concept of fragmentation used by Fahrig (1998) as follows: the level of fragmentation was positively and linearly related to the level of aggregation of a given physiognomy of the landscape. However, in Fahrig's model, the fragmentation level referred to only one physiognomy (breeding habitat), but in our model, it referred to both native physiognomy and intermediate physiognomy.

\section{Methods}

We created a software with the capability to simulate bi-dimensional landscapes with discrete, cell-based space. The properties of these landscapes are related to patterns concerning the amount and fragmentation of one or more physiognomies. This software can simulate individuals who can move, reproduce and die. The interaction of the individual with the landscape is related with different probabilities of execution of these three actions depending on which physiognomy an individual is on. This software can also simulate different landscape profiles and measure the time of permanence of a given population in each profile. Time is measured discretely in time steps. The actions of individuals occur simultaneously in one time step.

One of the objectives of this software was to replicate exactly the same simulation created by Fahrig (1998) to allow modification of Fahrig's model to investigate variables related to the quality of the matrix.

\section{Recovering Fahrig's model}

To certify that our software could replicate Fahrig's results, we simulated landscapes exactly as was simulated in her model. Binary landscapes (native and harsh physiognomy only) and the relation of the individuals with the landscape were the same (same probability of death, reproduction and movement depending on physiognomy). We then executed the same analyses in Fahrig's study and compared results. The first analysis was the simple effect of fragmentation on species permanence. All parameters 
in Fahrig's model maintained the default value (defined by her), and only the

fragmentation parameter was altered. This analysis revealed the effect of fragmentation significant correlation $(\mathrm{rho}=0.372 ; p<<0.01)$ although the residuals were high (Fig. 1). Because of the stochastic nature of the model, we expected high residual values even when comparing simulations ran by the same model. Fahrig's study also analyzed the effect of the other factors (e.g., proportion of landscape coverage, maximum occupancy of each cell, mortality probability in the matrix, and movement probability) on the relationship between fragmentation and the permanence of populations by fixing all other parameters in default values and varying only the parameters of interest and fragmentation level. Fahrig reported the result of some of these effects. In our study, we compared our results with those of Fahrig's study demonstrating an almost precise superposition of graphs from both studies and significant Spearman correlations between each set of data (inclination of the relationship between fragmentation and populations' permanence time) as follows: cover of native physiognomy, COVER (rho=0.934; $p<<0.01$ ); maximum number of individuals per cell, MAXOCC ( $\mathrm{rho}=0.915$; $p<<0.01$ ), probability of movement in native physiognomy, MOVE (rho=0.955; $p<<0.01$ ); maximum distance movement in a time step, MAXDIST (rho=0.952; $p<<0.01$ ); and disturbance probability, DPROB (rho=0.885; $p<<0.01$ ) (see S1 Fig).

These results indicated that our software replicated Fahrig's model allowing the modification of Fahrig's model to explore new factors.

\section{New model}

The second stage of our study analyzed the changes in the relationship between fragmentation and the permanence of a population caused by two other factors that could be translated into matrix quality. In Fahrig's model, the breeding habitat was a favorable physiognomy, the fitness of the population was the highest, and the matrix was conceived as a homogeneous extremely harsh environment that could maintain no 
a

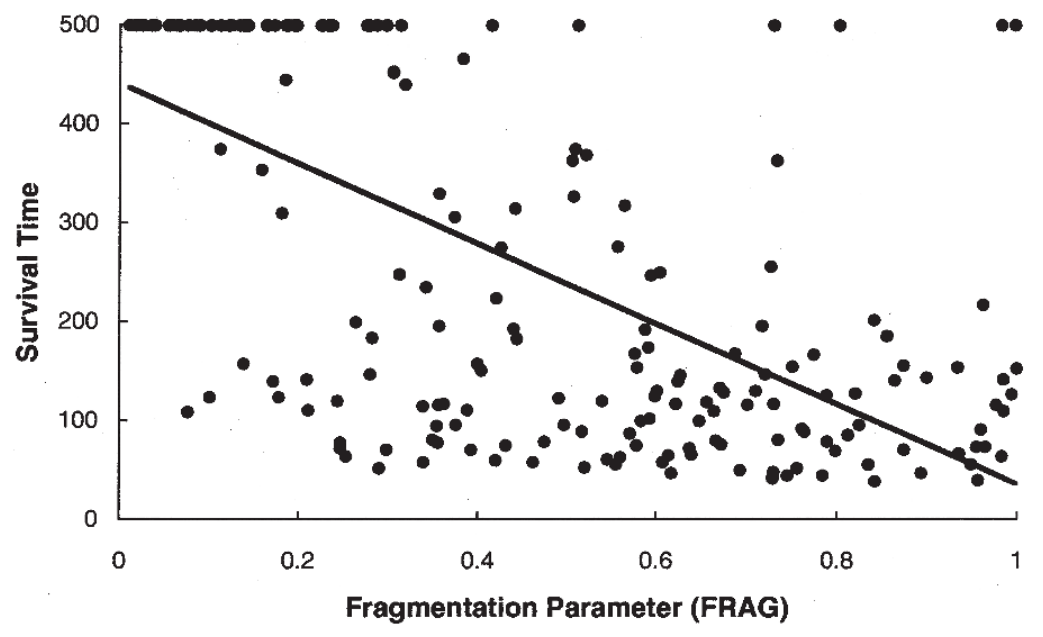

b

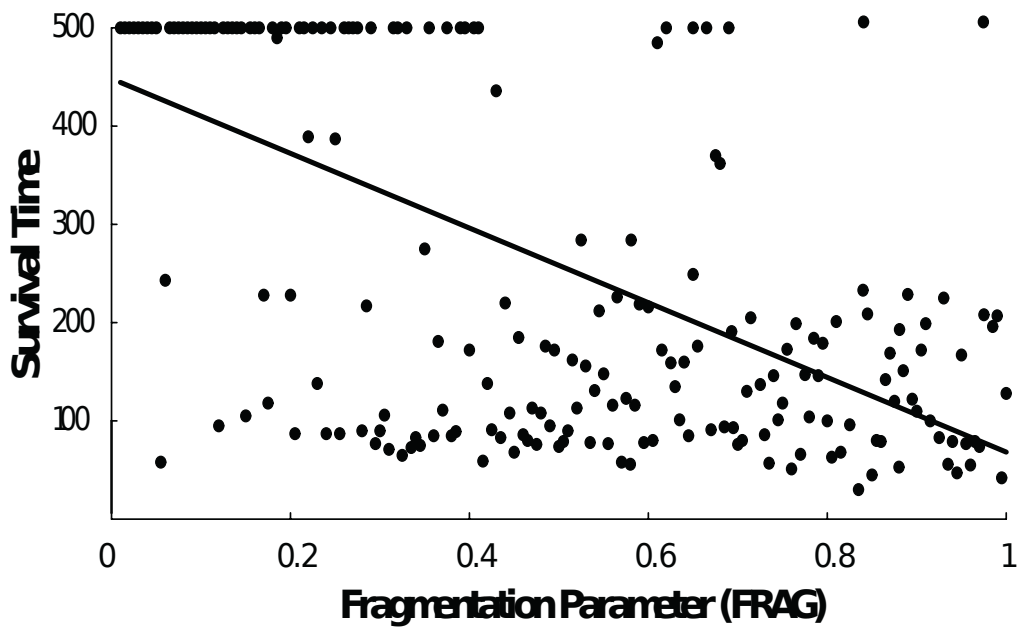

C

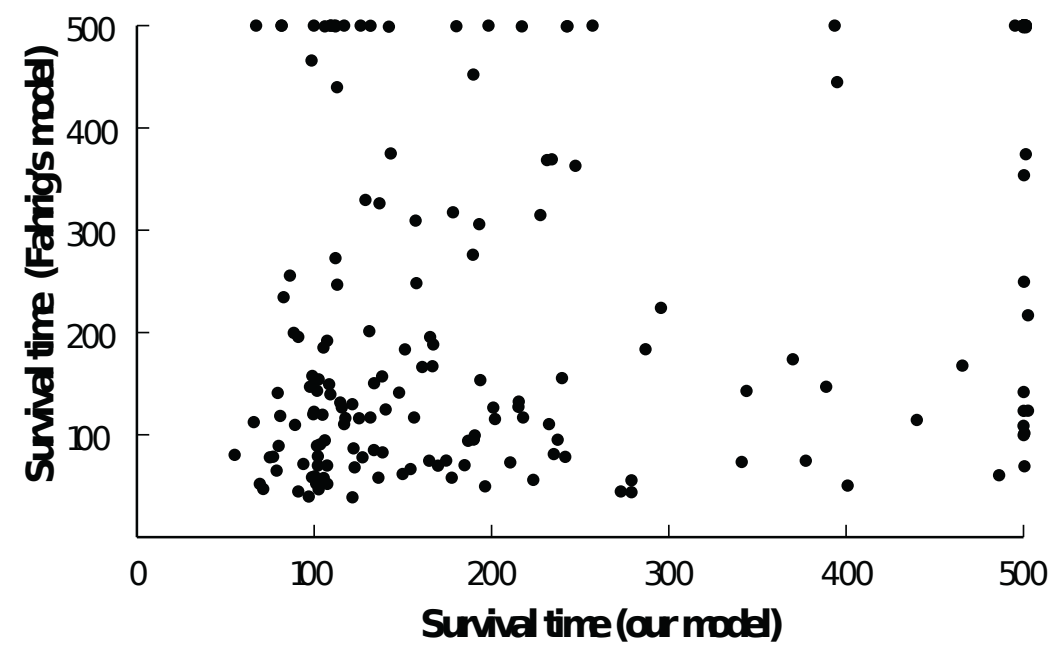

Figure 1. Relationship between fragmentation of native physiognomy (FRAG) and survival time based in 200 simulations. All other parameters where hold in default as defined by Fahrig (1998). The graph 'a' shows the result of our model, the graph 'b' shows the result for the original model (extracted from Fahrig 1998 - Figure 7). Graph 'c' shows the correlation between these two sets of data 
population. In our model, we conceived the most favorable habitat as the physiognomy

147 where the population evolved to find the optimum set of elements that maximize its survival and reproduction chance. The crucial difference is in the conception of the matrix. In our model, the matrix is this heterogeneous area that could have some harsh physiognomies but also some usable elements even though not as easily as in the native physiognomy. The proportion and the usability of these elements could vary from landscape to landscape. The two factors to be explored in our model represent the amount of intermediate physiognomy in the matrix (COVERM) and the usability level of this physiognomy (USABILITY). With these two new parameters, we generated landscapes with all combinations of the proportion of usable elements in the matrix and the level of usability of these elements.

Disregarding the previous cited modifications, our new model is largely based on Fahrig's model. Thus, we do not justify every described property of the model in this study. The default values for the factors in Fahrig's model were those values in which fragmentation had the higher effect on the permanence of the population. We used these set of values to make our analysis of the influence of the matrix quality.

\section{The model description}

The description of the model follows the ODD protocol (overview, design concept, and details) for describing the individual based model (Grimm et al, 2010).

Purpose The purpose of this model is to understand what is the relationship between usability of intermediate physiognomy and the amount of these elements in the matrix, and population extinction due to fragmentation of habitat. 2.3.2 Entities, state variables and scale

Our model was conceived with three hierarchic classes as follows: the hierarchic lower class is the individual class; the intermediate class is the cell class; and the higher class is the landscape class. The hierarchy is defined by spatial envelopment. Units of the class individual dwell in units of the class cell, and cells are the particles of the landscape class. Each of these classes have its own set of state variables (Table 1).

Individual class: Individuals were conceived in the exact same way of the original model. In each time step, individuals interact with the cell in which they are. Each 
Table 1. List of parameters and respective values used in the computational study.

\begin{tabular}{|c|c|c|c|}
\hline Class & Parameter & Description & Value \\
\hline \multirow[t]{9}{*}{ Landscape } & AREA & $\begin{array}{l}\text { Number of cells of the landscape } \\
\text { unit }\end{array}$ & $900(30 \times 30)$ \\
\hline & COVER & $\begin{array}{l}\text { Proportion of native physiog- } \\
\text { nomy in the landscape unit }\end{array}$ & 0.10 \\
\hline & DPROB & $\begin{array}{l}\text { Proportion of cells disturbed by } \\
\text { time-step }\end{array}$ & 0.05 \\
\hline & FRAG & $\begin{array}{l}\text { Fragmentation index of the native } \\
\text { and intermediate physiognomies }\end{array}$ & $0.01-1.00$ \\
\hline & USABILITY & $\begin{array}{l}\text { Usability of the intermediate } \\
\text { physiognomy compared to native } \\
\text { physiognomy }\end{array}$ & $10 \%-90 \%$ \\
\hline & N_USABILITY & $\begin{array}{l}\text { Usability of level of the native } \\
\text { physiognomy }\end{array}$ & $100 \%$ \\
\hline & COVERM & $\begin{array}{l}\text { Proportion of matrix covered by } \\
\text { intermediate physiognomy }\end{array}$ & $0.00-1.00$ \\
\hline & NIND & $\begin{array}{l}\text { Starting number of individuals in } \\
\text { the simulation }\end{array}$ & 500 \\
\hline & H_USABILITY & $\begin{array}{l}\text { Usability level of harsh physiog- } \\
\text { nomy }\end{array}$ & $0 \%$ \\
\hline \multirow[t]{4}{*}{ Cell } & cellType & Type of physiognomy & $\begin{array}{l}\text { Native/intermadiate } \\
\text { harsh }\end{array}$ \\
\hline & cellX & $\begin{array}{l}\text { Horizontal coordinate of the cell } \\
\text { in the cell grid }\end{array}$ & $0-29$ \\
\hline & cellY & $\begin{array}{l}\text { Vertical coordinate of the cell in } \\
\text { the cell grid }\end{array}$ & $0-29$ \\
\hline & $\operatorname{maxOcc}$ & $\begin{array}{l}\text { Maximum number of individuals } \\
\text { per time step }\end{array}$ & 10 \\
\hline \multirow[t]{8}{*}{ Individual } & dmort 3 & $\begin{array}{l}\text { Probability of death by distur- } \\
\text { bance (if the cell is disturbed in } \\
\text { current time step) }\end{array}$ & 0.10 \\
\hline & Use & $\begin{array}{l}\text { Perception of the usability of in- } \\
\text { habited cell }\end{array}$ & $0 \%-100 \%$ \\
\hline & indX & $\begin{array}{l}\text { Horizontal coordinate of the indi- } \\
\text { vidual in the cell grid }\end{array}$ & $0-29$ \\
\hline & ind $Y$ & $\begin{array}{l}\text { Vertical coordinate of the individ- } \\
\text { ual in the cell grid }\end{array}$ & $0-29$ \\
\hline & maxDist & $\begin{array}{l}\text { Maximum distance that can be } \\
\text { walked in a single time-step }\end{array}$ & 4 \\
\hline & Mort & Probability of death per time step & $0.05-0.50$ \\
\hline & Move & $\begin{array}{l}\text { Probability of movement per time } \\
\text { step }\end{array}$ & $0.50-1.00$ \\
\hline & rProb & $\begin{array}{l}\text { Probability of reproduction per } \\
\text { time step }\end{array}$ & $0.00-0.50$ \\
\hline
\end{tabular}


individual has a probability to die (mort), reproduce (rProb) and move to another cell (move). These three probabilities change linearly depending on the usability of the inhabited cell. Higher usability results in lower probabilities of death and movement and higher probabilities of reproduction. The perception of the individuals is associated with the perception of the usability of the cell they inhabit (USABILITY). If the cell in which a given individual currently inhabits is disturbed, it will have an additional probability 0.1 of death by disturbance (dMort). Each individual has parameters defining in which cell they inhabit (coordinates in the cell grid indX and ind $Y$ ). Another feature of the individual is that it might move in a given time step, and if it does, it will move a random distance (in cells) up to four cells in that time step (maxDist $=4)$ at a random direction.

Cell class: A unit of this class is a square object that can be occupied by up to ten individuals at the same time step $(\operatorname{maxOcc}=10)$. Each cell has the information of which position it has in the cell grid (coordinates cellX and cellY). In our model, each cell will be one of the three different types, namely, native physiognomy, intermediate physiognomy and harsh physiognomy, thus differing from Fahrig's model in which each cell could belong to only two classes, namely breeding habitat or matrix.

Landscape class: A unit of this class is a bidimensional square object composed of a cell grid of 900 cells (30 x 30) (AREA). As a consequence of each cell being one of the three types of physiognomy, the landscape always has a given proportion of native, intermediate and harsh physiognomy. Each landscape has a given proportion of intermediate physiognomy (COVERM) and harsh physiognomy that when summed, must reach $90 \%$ of the number of cells in the landscape. Each landscape has a given level of aggregation between the cells of the same type (FRAG), and it has a proportion of 0.05 of the cells disturbed in the landscape. The disturbed cells are randomly assigned in the beginning of each time step exactly like in the original model. The landscapes have periodic boundary conditions (the edges of right and left, top and bottom are joined continuously).

Routines Landscape construction routine: Landscape profiles are defined by combinations of the following three parameter values: COVERM, USABILITY, and FRAG. COVERM defines how much of the matrix is covered by the intermediate 
physiognomy. USABILITY defines the usability of this intermediate physiognomy.

FRAG defines the aggregation level of the native physiognomy type cells and of the intermediate physiognomy type cells. As the FRAG parameter increases, a higher number of more isolated fragments of native physiognomy and intermediate physiognomy occurs in the landscape. We used the exact same algorithm used by Fahrig to implement fragmentation of breeding habitat in her model. The difference in our model is that it applies to both native physiognomy and intermediate physiognomy. Primarily, all cells are defined as harsh physiognomy, and they will be assigned as native physiognomy or intermediate physiognomy in the course of this routine. The focal physiognomy is also selected randomly (native physiognomy or intermediate physiognomy). The cells are selected one by one and assigned with the focal type of physiognomy. However, this assignment is conditioned to a single rule that might be ignored. The rule is that a selected cell is only assigned with the focal physiognomy if any other neighboring cell is already assigned with that physiognomy, and this rule induces aggregation of the cells of the same physiognomy. FRAG is the probability to ignore this rule, and it assigns the selected cell as the focal physiognomy independently of the physiognomy of its neighboring cells. The outcome of this routine is conditioned to the value of FRAG. If FRAG equals 1.0, the rule cited above is completely ignored, and the cells will be assigned randomly as they are selected. However, if FRAG is too low, the first rule is applied most times; thus, it is likely that cells of these two physiognomies occur aggregated within their types. If a cell is not assigned in the routine, the focal physiognomy is not changed, and another random cell is selected. If the selected cell is assigned, then the focal physiognomy changes, and the routine is repeated. This routine is repeated while the number of cells intended for both physiognomies (defined by COVER and COVERM depending on the physiognomy) is not reached. In the end of the process the landscape profile will have a proportion COVER of native physiognomy, and a proportion COVERM of intermediate physiognomy and it will be ready to run its first time-step.

Time step routine: In the beginning of each time step, the cells are selected randomly one by one, and each selected cell executes its internal routine. In each cell, the same process is applied to individuals as follows: the individuals are selected randomly one by one, and each executes its own individual routine. When an individual 
is selected, it randomly selects the order in which it will execute its three possible

actions (die, move and reproduce). Due to the probabilistic nature of these events, one individual might die, move and/or reproduce in one time step, but it also could do nothing once it is selected. After all individuals have been selected and have had the chance to execute their three actions, another cell is selected. After all cells have been selected, the outcomes of individual actions are updated as follows: individuals who have moved are placed in the new cells; individuals who died are deleted; and cells in which individuals reproduced receive one new individual for each successful reproduction. If there are any cells with more than 10 individuals, the individuals in these cells are randomly deleted until there are only 10 individuals. This event is the only implementation that brings the concept of dense-dependent relationships. After this step, another time step takes place. This routine is repeated until the number of individuals equals zero or the number of time steps equals 500. The number of time steps, FRAG, COVERM and USABILITY are then registered.

All routines and subroutines are described in detail, graphically in S2 Fig.

Design concept Emergence: The main emergent property of this model is the relationship between population permanence and the structural differences of the landscape. However, the patterns generated by the combination of FRAG, COVER and COVERM might also be considered an emergent property of the model.

Perception: Individuals know the usability level of the habitat in which they inhabit, which influences the probability of movement they have. However, individuals do not have a perception of other cells of the landscape, which justifies why individuals who are in the native physiognomy have a chance of movement even though it is the best type of physiognomy it will find in the landscape.

Interactions: The interaction of an individual is basically with its inhabited cell. Being inside a cell gives the individual the perception of the cell usability level, thus altering the probabilities of death, reproduction and movement. The relationships between the usability of the inhabited cell and the probabilities of executing the actions are shown in Figure 2. The interaction between individuals is implicitly introduced through death by overpopulation in each cell. Any other decision of the individual (reproduction, natural death and movement) is independent of other individuals or

241 242 
density of individuals. Stochasticity: The construction of each landscape has a

stochastic component. The landscape construction involves the random selection of cells in several steps, and the aggregation pattern is set by a probability (FRAG). The cells disturbed in each time step are also randomly selected. Moreover, the behavior of each individual is dictated by probabilities (mort, move and rProb), which vary according to the cell inhabited that in turn depends on the decisions taken in the previous turn.

\section{Analysis}

Before the explanation of the analysis process, it is essential that some terms be clarified.

"Simulation" is a complete routine of creating a landscape with its set of parameters and individuals, and letting the individuals interact with the landscape until the population goes extinct or the number of time steps reaches 500. Every simulation must register the landscape profile as the independent factor and the time step in which the population became extinct (or not if the simulation reached 500 time steps) as the dependent variable.

"Landscape profile" is the set of parameters used to construct a given landscape unit. As our model has a stochastic component in the construction of the landscape, in different simulations, the same landscape profile could generate landscapes with different designs.

Initialization The simulations are always initiated with 500 individuals (NIND) randomly placed in the landscape. The level of usability of the native physiognomy is considered 100\% (N_USABILITY). The level of hostility of the harsh physiognomy is $0 \%$ (H_USABILITY). The level of hostility of the intermediate physiognomy is a given number between $0 \%$ and 100\% (USABILITY). An individual dwelling in a cell with a usability level that equals $100 \%$ will be facing the exact same breeding habitat described in Fahrig's model. Therefore, the probability of movement/death/reproduction per time step of this individual will be the same, 0.5/0.05/0.5. In a cell with a usability level that equals $0 \%$, an individual will be facing the exact same matrix described in Fahrig's model. Therefore, the probability of movement/death/reproduction of this individual will be 1.0/0.5/0.0 (see Fig. 22). 


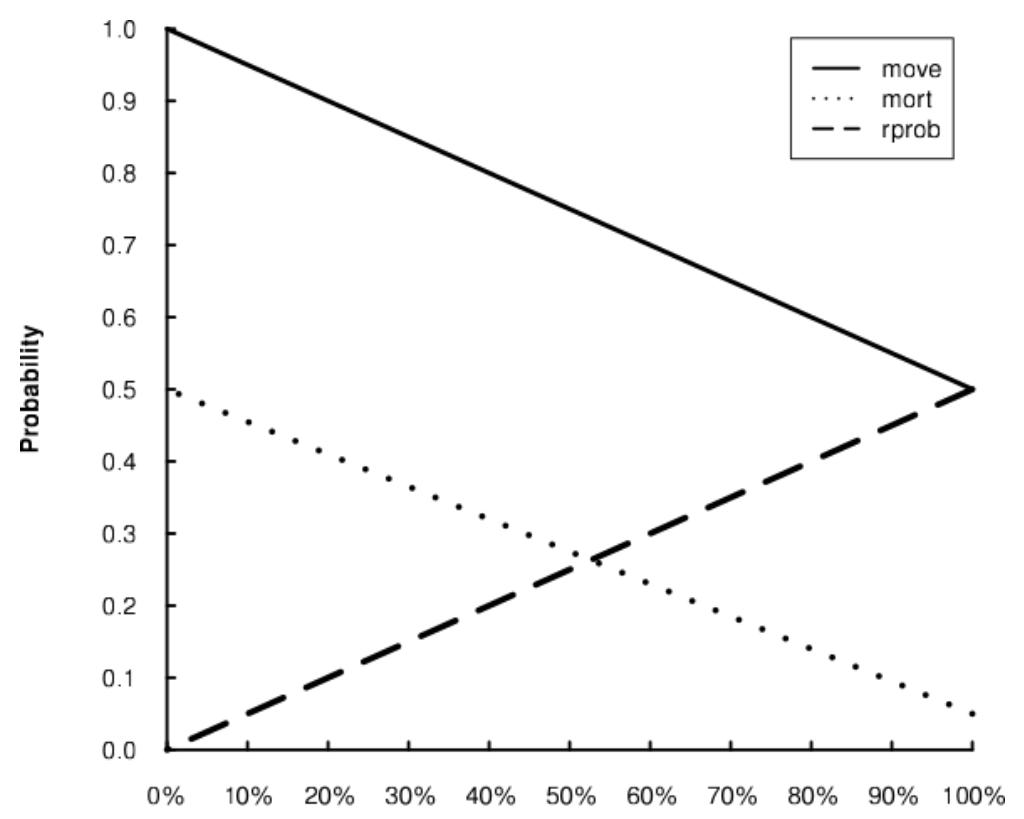

USABILITY

Figure 2. Relationship between the usability level of the cells and the probability of execution of movement (move), death (mort) and reproduction (rprob) by a single individual in one time step

As the objective of this model is to evaluate the effect of the interaction among FRAG, USABILITY and COVERM, these parameters were systematically combined to generate different landscape profiles (Table 11. However, the same combination of these parameter landscapes can have different designs because the landscape construction routine has many stochastic components.

Observation To systematically analyze the effects of COVERM and USABILITY, we held the proportions of native physiognomy in the default value $(10 \%$ of the landscape cells). Thus, in all of our simulations, the matrix area was $90 \%$ of the landscape cells. We ran simulations with 9,000 different landscape profiles: 900 different matrix types were generated by the combination between COVERM (0.00 to 0.99, increment of 0.01) and USABILITY (10\% to $90 \%$, increment of $10 \%)$ and each of these landscapes were simulated with 10 different degrees of fragmentation FRAG (0.1 to 1.0, increment of 0.1). Because the same landscape profile could generate different landscape designs each simulation was replicated 15 times for each of the 9000 landscape profiles resulting in a total of 135,000 simulations in the entire study.

At the end of each simulation, we recorded in which time step the population 
became extinct and the landscape profile. Thus, for each landscape profile, there was a $\quad 317$ mean of 15 populations' extinction time. If the population did not become extinct until 318 the 500th time step, the time of permanence recorded was 500.

\section{Results}

Our model assumes that in a situation in which the landscape is composed of $10 \%$ of breeding habitat and the matrix is a homogeneous, very hostile physiognomy, the effect of fragmentation exists as follows: with high levels of fragmentation, the population will become extinct within a few time steps; and with low levels of fragmentation, the population will thrive for an undetermined time. We then analyzed the effect of the matrix quality starting from this scenario.

Fahrig stated that of all possible combinations of parameters used in her study to define the landscape, fragmentation had an effect on survival time in only $0.4 \%$ of the combinations (Fahrig, 1998). We observed that within this proportion, fragmentation would have an effect on the survival time of the populations in only $57 \%$ of the possible matrix types. We observed that of the 900 types of matrix qualities simulated, the slope of the relationship between fragmentation and the permanence time of the population was less than zero in $513(57 \%)$ of the matrix types (Fig. 3). As expected, none of these relationships was significantly positive.

In situations where the usability of the intermediate physiognomy is too low, the effect of fragmentation on the survival time of this population is unchanged. However, as the usability of this physiognomy increases, the situations in which we can observe the effects of fragmentation become less frequent. As the usability of the intermediate physiognomy decreases (becoming more similar to the harsh physiognomy), the greater is the proportion of this type of physiognomy necessary to suppress the effect of fragmentation. When the usability of the intermediate physiognomy equals $30 \%$ of the efficiency the individuals use the native physiognomy (USABILITY $=30 \%$ ), the effect of fragmentation begins to be suppressed. If the matrix is completely covered by a physiognomy of this type, the effect of fragmentation ceases indicating that the populations always survive for an undetermined time regardless of native physiognomy fragmentation level. Thus, higher utilization efficiency of the intermediate physiognomy

322 323 324 325 326 327 328 329 330 331 332 333 334 335 336 337 338 339 340 341 342 343 344 345 346 


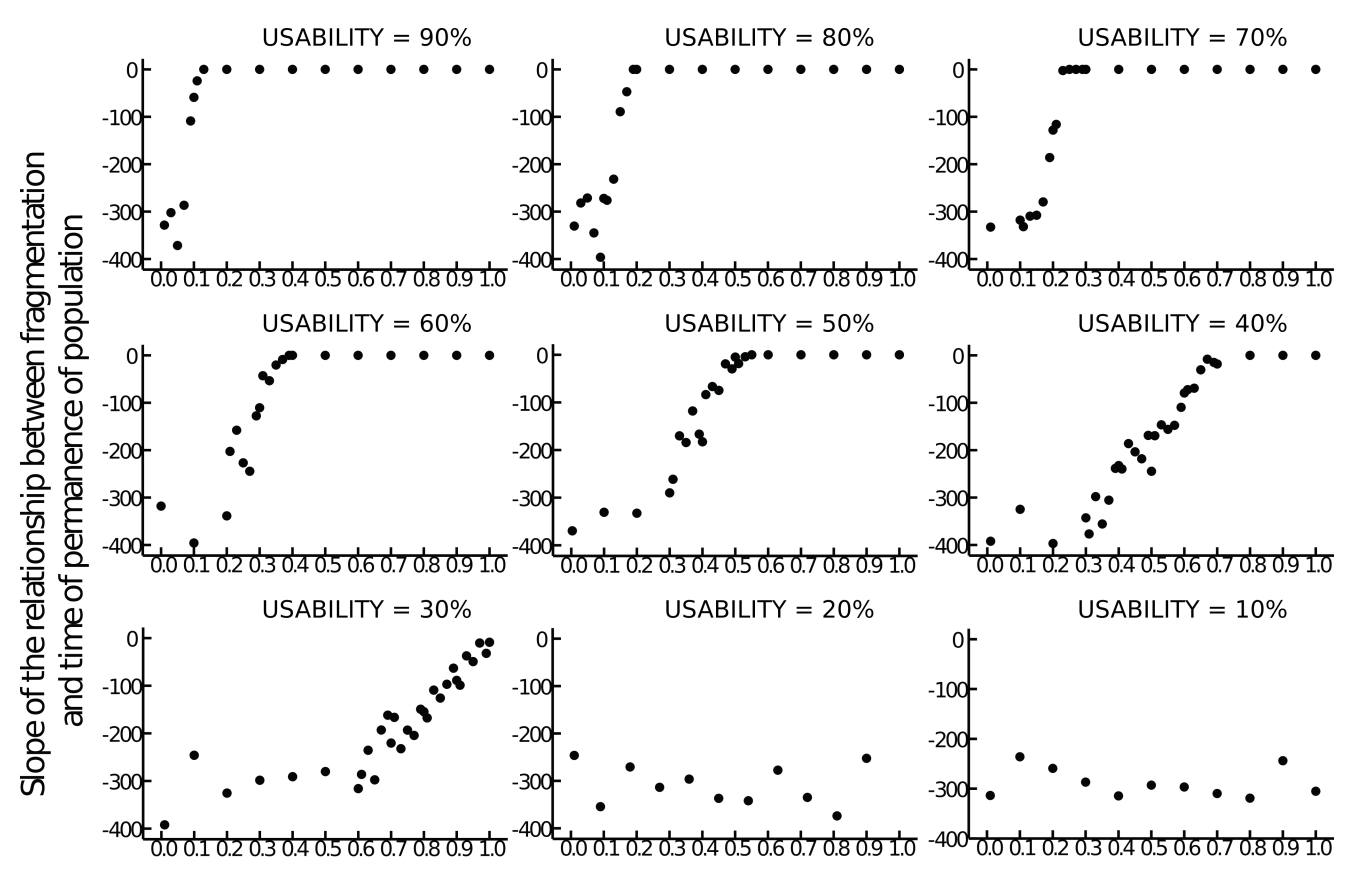

Proportion of the matrix covered by intermediate physiognomy (COVERM)

Figure 3. Change in the fragmentation's effect on population permanence caused by the change in the proportion of the matrix covered by intermediate physiognomy. Each graph shows the changes for intermediate physiognomies with different levels of hostility. Each point in the graphs was obtained from 15 replicates of the simulations ran with each given value of COVERM combined with each of the 10 values of FRAG $(0.1,0.2 \ldots$ 1.0) reaching 150 simulations per point

results in a lower proportion of it in the matrix that is necessary to completely suppress the effect of fragmentation. An interesting pattern observed is the relationship between the usability level of intermediate physiognomy and the threshold of fragmentation effect. The proportion of the matrix covered by intermediate physiognomy necessary to completely suppress the effect of fragmentation fallows linearly the usability level until a certain point. For example, with USABILITY $=90 \%$, only $10 \%$ of the matrix cells needs to be of intermediate habitat; with USABILITY $=80 \%$, only $20 \%$; with $\ldots$

USABILITY $=50 \%$, half of matrix cells need to be of intermediate physiognomy to suppress the fragmentation effect. However, below that level of usability, the relationship ceases to be linear. With USABILITY $=40 \%$ it is necessary intermediate physiognomy covers $70 \%$ of the matrix cells. With USABILITY $=30 \%$ fragmentation effect is only suppressed if all matrix is covered by intermediate physiognomy (Fig. 3). 358 Usability efficiency below $30 \%$ have no capability of suppressing fragmentation effect. 


\section{Discussion}

In our model, we observed that the usability and proportion of the intermediate physiognomy in the matrix interact altering its effect on the survival of populations in landscapes with different levels of fragmentation. This observation corroborates previous studies using highly specialized organisms to test fragmentation (Harrisson et al, 2013; Holland and Bennett, 2010, Johnstone et al, 2010; Nimmo et al, 2013) as our expectation suggests that fragmentation should not be important for organisms that can use the matrix with some efficiency.

These results help us understand how different elements in the matrix might suppress the decline in populations and, consequently, the loss of species. If some element in the matrix is similar to the native physiognomy, an organism is able to use it as a reproduction spot or a trampoline to reach distant fragments of the native physiognomy as argued by Ewers and Didham (2006), which should increase the population's abundance in the landscape, thus lowering its chance of extinction. It is reasonable to expect that the efficiency of use of the same element in the matrix changes between populations of different species because each species has its own needs (MacArthur and MacArthur, 1961). Therefore, a landscape with a more heterogeneous matrix (i.e., with more different types of intermediate physiognomies), should sustain a higher richness of species. We encourage the use of future models to explore the relationship between heterogeneity of the matrix and species richness in a landscape.

Fahrig stated that it would be interesting to know if a matrix could increase the effect of fragmentation in any case (Fahrig, 1998). The situations in which fragmentation does not have any effect on the survival time of the population can be classified into two types. In the first type, landscape properties are too favorable to the population. Therefore, the population persists in the landscape regardless of how the landscape is structured, e.g., when the coverage area of the native physiognomy is very large. In the second type, the opposite trend occurs where the properties of the landscape are so unfavorable that the population goes extinct quickly regardless of the landscape structure, e.g., when the coverage area of the breeding habitat is extremely low. In our model, we assume that the matrix described by Fahrig was the most hostile possible; thus, any changes made in the matrix in our model create a less hostile overall 
matrix.

Any reduction or increase in the effect of fragmentation caused by changes in the matrix in our model is due to increased chance of survival of the population and, therefore, the permanence time. The situations in which changes in the matrix increase the effects of fragmentation are those in which the landscape is too unfavorable, and these populations do not survive for long regardless of fragmentation. An improvement of matrix quality allows these populations to survive longer. In this new situation, changes in fragmentation levels should be again important to the permanence of the population in the landscape. In our model, the intermediate physiognomy serves as a surrogate to the coverage area of the breeding habitat. Lower usability of the intermediate physiognomy results in larger coverage areas of such habitat necessary to suppress the effect of missing or isolation of fragments of the breeding habitat. This result shows that the concept of matrix is in agreement with several studies showing that the matrix can be used as a secondary habitat in relation to the optimum habitat for the population (Bender and Fahrig, 2005, Hodgson et al, 2007, Prevedello and Vieira, 2010, Umetsu and Pardini, 2007). Our results reinforce the argument that fragmentation is important for the permanence of populations in only a few situations. Moreover, if the population in question can somehow use the matrix, it is even more unlikely to be affected by fragmentation.

This study revealed some values of the parameters in which the relationship between the matrix quality and the survival of population changes in the landscape. A correspondence exists between the measure of efficiency of utilization of the intermediate physiognomy with the necessary proportion of it in the matrix to suppress the effect of habitat loss. With $90 \%$ efficiency of utilization of an intermediate physiognomy, $10 \%$ of the matrix covered by it should suffice to suppress the effect of fragmentation. With $80 \%$ efficiency, $20 \%$ of the matrix covered by the intermediate physiognomy should be sufficient. This trend continues until $40 \%$ of efficiency where this relationship changes and $70 \%$ of the matrix is needed to be covered by intermediate physiognomy. The existence of this trend is a testable hypothesis derived from this model. This kind of information should aid in the decisions of what kind and how much of these elements are necessary for some populations to thrive in a determined landscape. And the threshold indicates that there is a level of usability of these 
intermediate elements below which the fragmentation effect would not be suppressed independently of how much of it would exist in the matrix. However, the applicability of this information to conservation is dependent of a measure of efficiency utilization of the intermediate physiognomy. Identifying three types of physiognomy in a natural landscape should not be a difficult task. However, developing an index to quantify the efficiency of use of each physiognomy by a determined population might be difficult.

With the appropriate index for a given population, model of this kind could be used to generate even more precise previsions about the permanence of populations in the landscape and how to manage the elements in a matrix.

Our model assumes that different species that can use the matrix in equivalent ways will suffer the effects of fragmentation equivalently. We encourage future studies that test this hypothesis empirically. We emphasize that previous studies finding a strong effect of fragmentation for specialist organisms are working with a small amount of biodiversity that cannot use elements of the matrix efficiently (Jules and Shahani, 2003; Wiens, 2009). We also emphasize that a measure of the usability of the matrix by the focal population could be essential to predict its permanence in the landscape.

\section{Acknowledgments}

We thank L. Fahrig for her kind help with our doubts about her model and for giving us the permission to use one of the pictures of her work. Travassos-de-Britto B was supported by the Coordenação de Aperfeiçoamento de Pessoal de Nível Superior (CAPES) with a master degree scholarship. Rocha PBL was supported by the Fundação de Amparo à Pesquisa do Estado da Bahia (FAPESB). Rocha PBL and Miranda JGV were supported by Conselho Nacional de Desenvolvimento Científico e Tecnológico $(\mathrm{CNPq})$ during this project.

\section{References}

Bender DJ, Fahrig L (2005) Matrix Structure Obscures the Relationship Between Interpatch Movement and Patch Size and Isolation. Ecology 86: 1023-1033 
Bélisle M, Desrochers A, Fortin MJ (2001) Influence of Forest Cover on the Movements of Forest Birds: A Homing Experiment. Ecology 82: 1893-1904

Didham RK, Hammond PM, Lawton JH, Eggleton P, Stork NE (1998) Beetle Species Responses to Tropical Forest Fragmentation. Ecological Monographs 68: 295-323

Drolet B, Desrochers A, Fortin MJ (1999) Effects of landscape structure on nesting songbird distribution in a harvested boreal forest. Condor 699-704

Ewers RM, Didham RK (2006) Confounding factors in the detection of species responses to habitat fragmentation. Biological Reviews 81: 117-142

Fahrig L (1998) When does fragmentation of breeding habitat affect population survival? Ecological modelling 105: 273-292

Fahrig L (2003) Effects of habitat fragmentation on biodiversity. Annual review of ecology, evolution, and systematics 487-515

Grimm V, Berger U, DeAngelis DL, Polhill JG, Giske J, Railsback SF (2010) The ODD protocol: a review and first update. Ecological modelling 221: 2760-2768

Harrisson KA, Pavlova A, Amos JN, Takeuchi N, Lill A, Radford JQ, Sunnucks P (2013) Disrupted fine-scale population processes in fragmented landscapes despite large-scale genetic connectivity for a widespread and common cooperative breeder: the superb fairy-wren (Malurus cyaneus). Journal of animal ecology 82: 322-333

Hodgson P, French K, Major RE (2007) Avian movement across abrupt ecological edges: differential responses to housing density in an urban matrix. Landscape and Urban Planning 79: 266-272

Holland GJ, Bennett AF (2010) Habitat fragmentation disrupts the demography of a widespread native mammal. Ecography 33: 841-853

Hovel KA, Lipcius RN (2001) Habitat fragmentation in a seagrass landscape: patch size and complexity control blue crab survival. Ecology 82: 1814-1829

Johnstone CP, Reina RD, Lill A (2010) Impact of anthropogenic habitat fragmentation on population health in a small, carnivorous marsupial. Journal of Mammalogy 91: $1332-1341$ 
Jules ES, Shahani P (2003) A broader ecological context to habitat fragmentation: why matrix habitat is more important than we thought. Journal of Vegetation Science 14: $459-464$

Kearney M (2006) Habitat, environment and niche: what are we modelling? Oikos 115: $186-191$

MacArthur RH, MacArthur JW (1961) On bird species diversity. Ecology 42: 594-598

Nimmo DG, Kelly LT, SPENCE-BAILEY L, Watson SJ, Taylor RS, Clarke MF, Bennett AF (2013) Fire Mosaics and Reptile Conservation in a Fire-Prone Region. Conservation Biology 27: 345-353

Pickett STA, Kolasa J, Jones CG (2010) Ecological Understanding: The Nature of Theory and the Theory of Nature. Academic Press

Prevedello JA, Vieira MV (2010) Does the type of matrix matter? A quantitative review of the evidence. Biodiversity and Conservation 19: 1205-1223

Reino L, Beja P, Araujo MB, Dray S, Segurado P (2013) Does local habitat fragmentation affect large-scale distributions? The case of a specialist grassland bird. Diversity and Distributions 19: 423-432

Ricketts TH (2001) The matrix matters: effective isolation in fragmented landscapes. The American Naturalist 158: 87-99

Rosenberg KV, Lowe JD, Dhondt AA (1999) Effects of forest fragmentation on breeding tanagers: a continental perspective. Conservation Biology 568-583

Saunders DA, Hobbs RJ, Margules CR (1991) Biological consequences of ecosystem fragmentation: a review. Conservation biology 18-32

Summerville KS, Crist TO (2001) Effects of experimental habitat fragmentation on patch use by butterflies and skippers (Lepidoptera). Ecology 82: 1360-1370

Umetsu F, Pardini R (2007) Small mammals in a mosaic of forest remnants and anthropogenic habitats - evaluating matrix quality in an Atlantic forest landscape. Landscape Ecology 22: 517-530 
Weldon AJ (2006) How corridors reduce Indigo Bunting nest success. Conservation

Biology 20: 1300-1305

Wiegand T, Revilla E, Knauer F (2004) Dealing with uncertainty in spatially explicit population models. Biodiversity \& Conservation 13: 53-78

Wiens JA (2009) Landscape ecology as a foundation for sustainable conservation.

Landscape Ecology 24: 1053-1065

\section{Supporting Information}

\section{S1 Fig}

Parameter comparison Comparisson between results of Fahrig s model (right) and our model (left) with relation to variations in specific parameters (Fahrig, 1998 - Figure $8,9,12,14,15)$. 

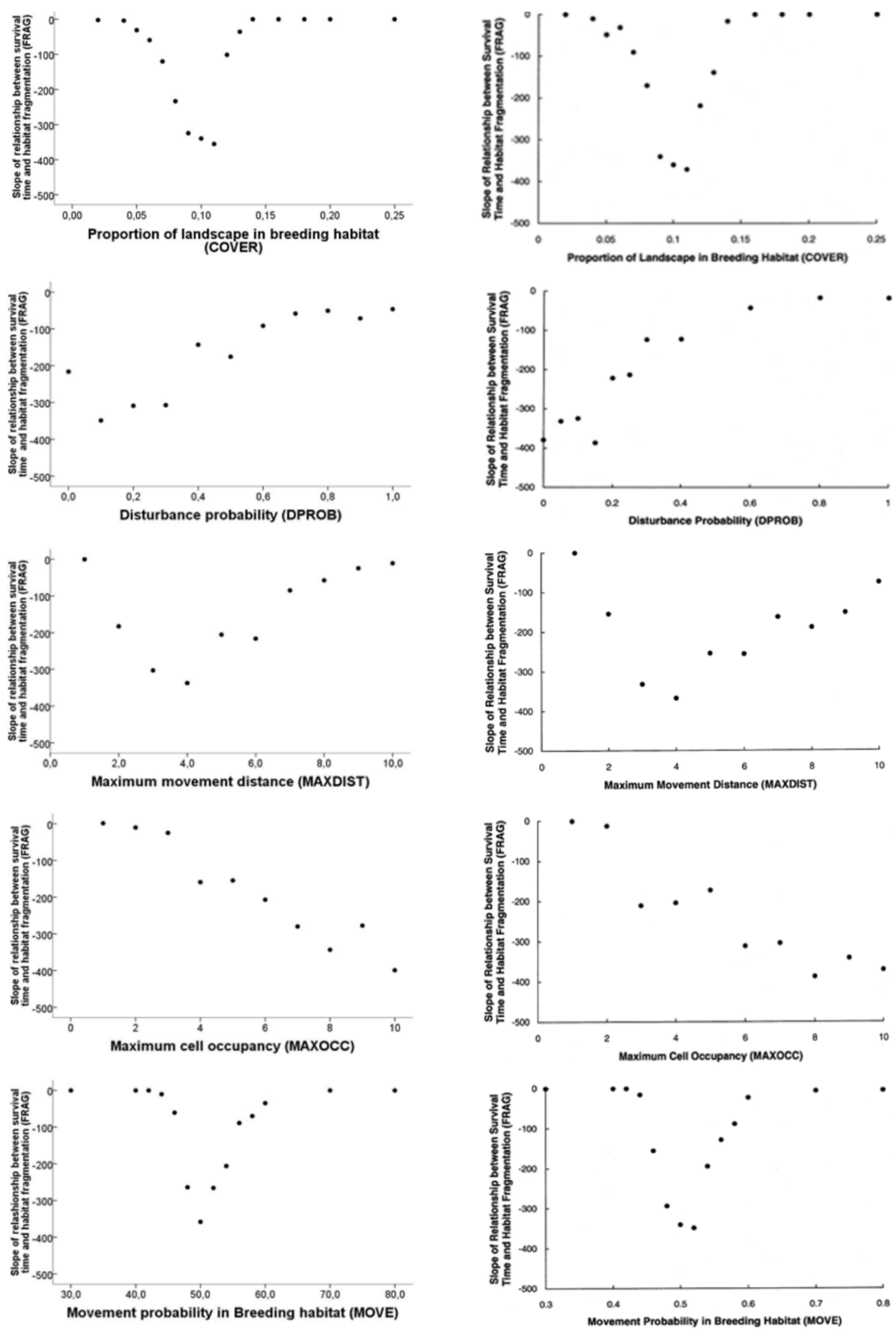


\section{S2 Fig}

Routines Algorithm executed by the software through the experiment. "Main routine" is the algorithm followed through a single simulation. "Sub-routine 1" is the algorithm setting properties of cells and consequentially the landscape design. "Sub-routine 2" is algorithm to set the disturbance pattern in each landscape. "Sub-routine 3" is the algorithm followed by each individual in each time step. "Sub-routine 4" is the algorithm executed by each cell to update death, birth and movement, and death by overpopulation in the cells. 


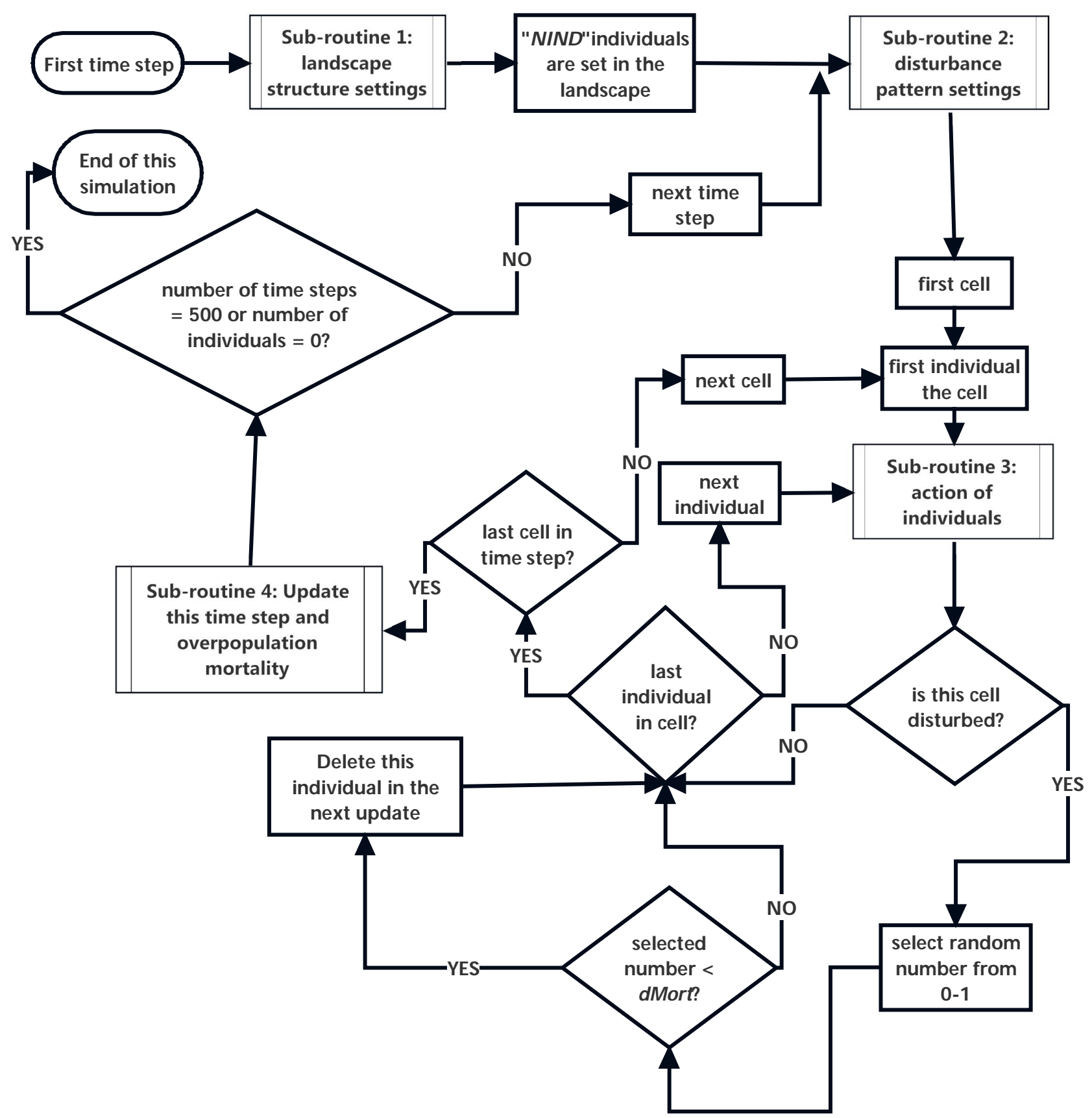

Main routine. Algorithm to be executed by the software to run a single simulation. 


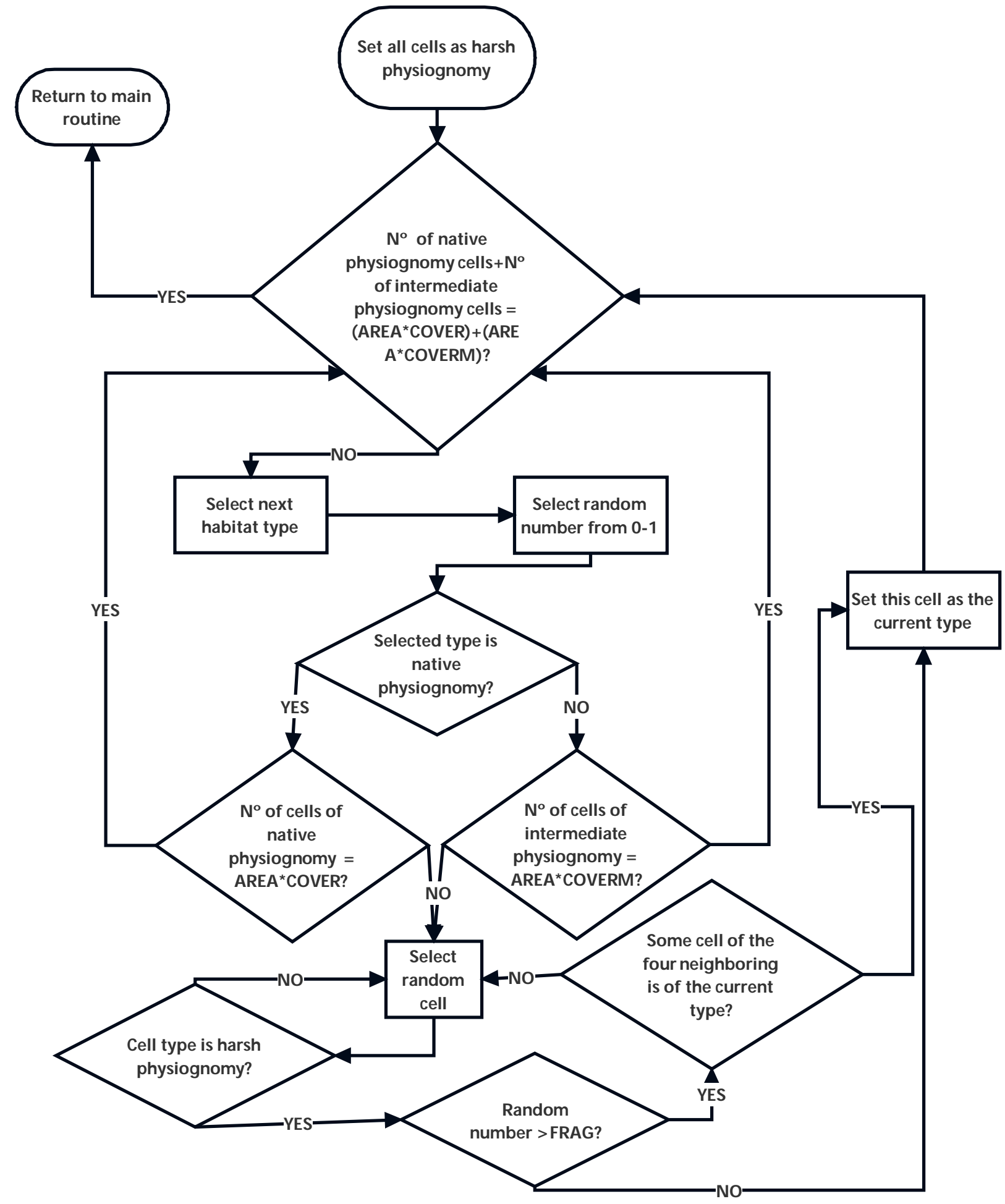

Sub-routine 1. Algorithm setting properties of cells and consequentially the landscape design. 


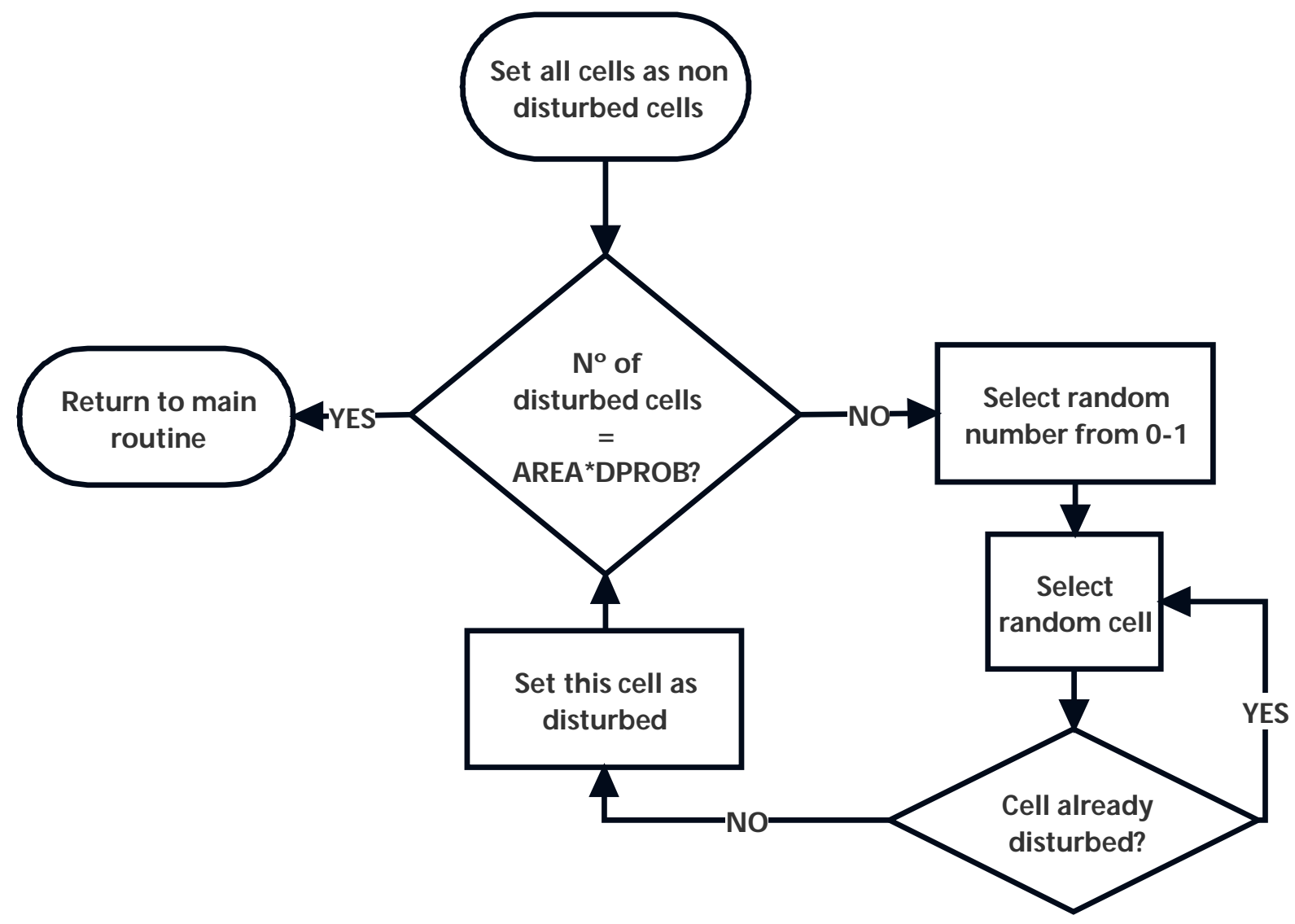

Sub-routine 2. Algorithm to set the disturbance pattern in each landscape. 


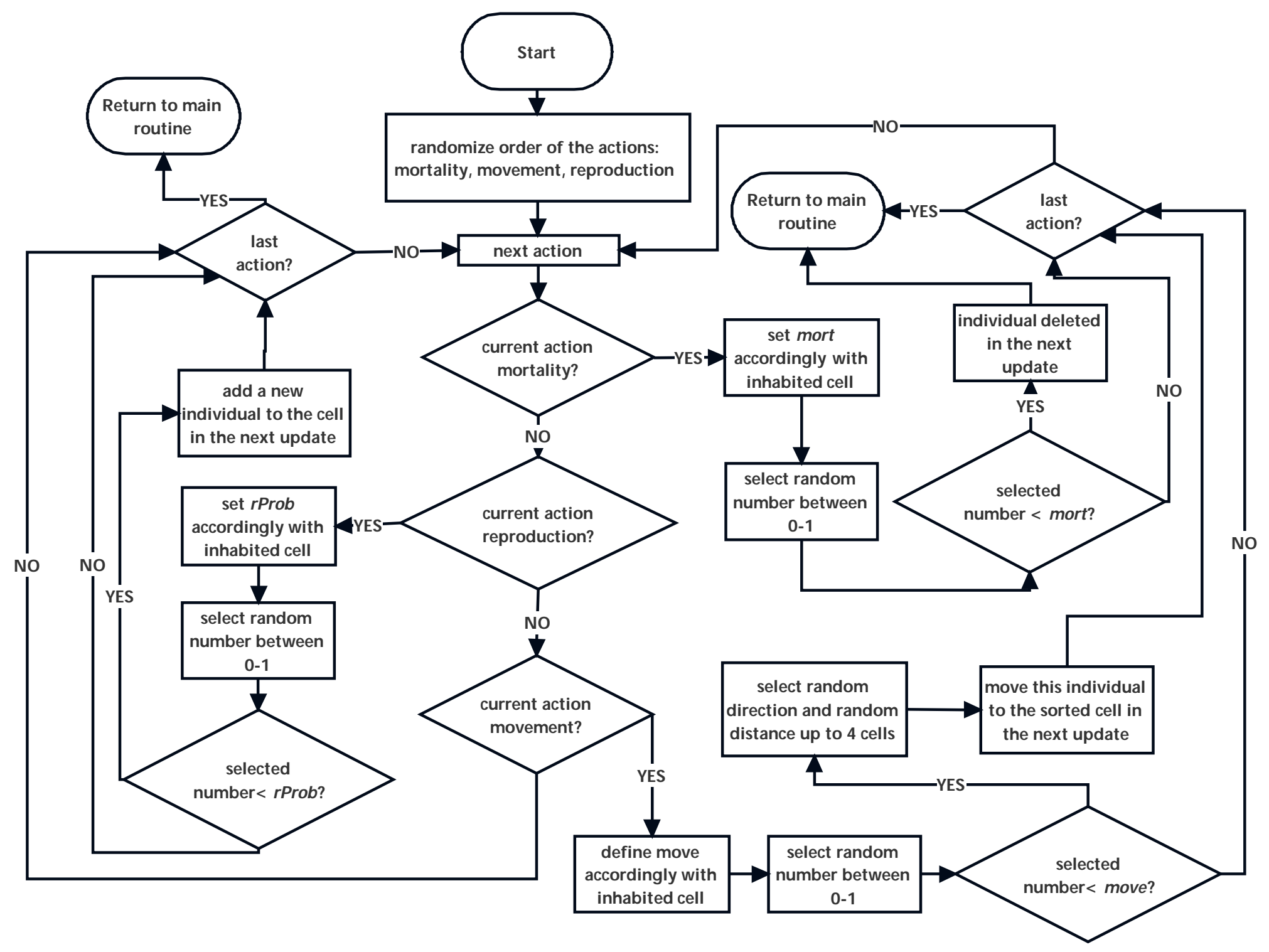

Sub-routine 3. Algorithm followed by each individual in each time step. 


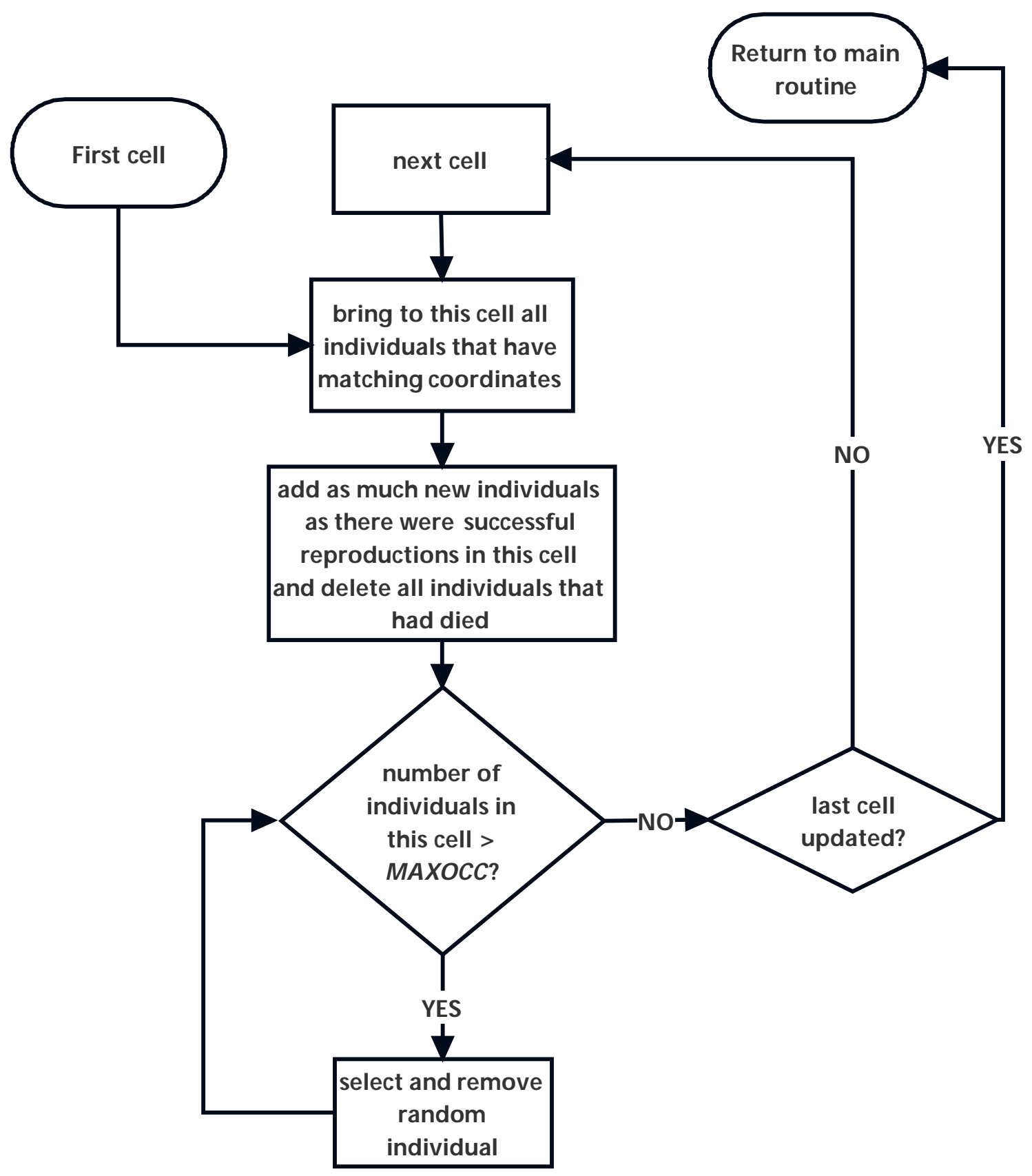

Sub-routine 4. Algorithm executed by each cell to update death, birth and movement, and death by overpopulation in the cells. 